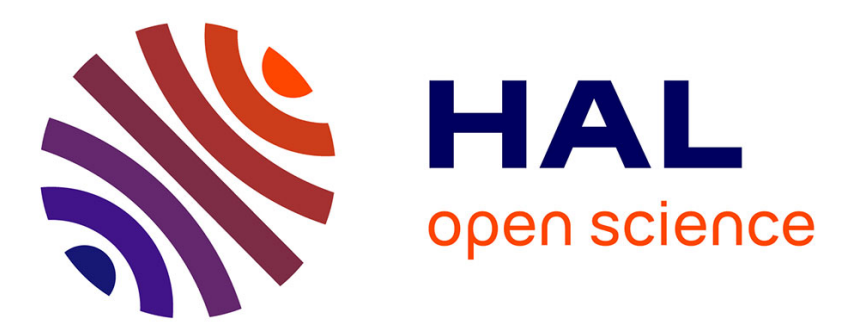

\title{
A reappraisal of the value of lateral spread response monitoring in the treatment of hemifacial spasm by microvascular decompression
}

\author{
Danusa O Neves, Jean-Pascal Lefaucheur, Daniel Ciampi de Andrade, \\ Mohammed Hattou, Rechdi Ahdab, Samar S Ayache, Caroline Le Guerinel, \\ Yves Keravel
}

\section{To cite this version:}

Danusa O Neves, Jean-Pascal Lefaucheur, Daniel Ciampi de Andrade, Mohammed Hattou, Rechdi Ahdab, et al.. A reappraisal of the value of lateral spread response monitoring in the treatment of hemifacial spasm by microvascular decompression. Journal of Neurology, Neurosurgery and Psychiatry, 2009, 80 (12), pp.1375. 10.1136/jnnp.2009.172197 . hal-00552766

\section{HAL Id: hal-00552766 https://hal.science/hal-00552766}

Submitted on 6 Jan 2011

HAL is a multi-disciplinary open access archive for the deposit and dissemination of scientific research documents, whether they are published or not. The documents may come from teaching and research institutions in France or abroad, or from public or private research centers.
L'archive ouverte pluridisciplinaire HAL, est destinée au dépôt et à la diffusion de documents scientifiques de niveau recherche, publiés ou non, émanant des établissements d'enseignement et de recherche français ou étrangers, des laboratoires publics ou privés. 


\section{A reappraisal of the value of lateral spread response monitoring in the}

\section{treatment of hemifacial spasm by microvascular decompression}

D O Neves, ${ }^{1,2}$ J-P Lefaucheur, ${ }^{1}$ D Ciampi de Andrade, ${ }^{1,2}$ M Hattou, ${ }^{2}$ R Ahdab, ${ }^{1}$ S S Ayache, ${ }^{1,2}$

C Le Guerinel, ${ }^{2}$ Y Keravel $^{2}$

${ }^{1}$ Service de Physiologie - Explorations Fonctionnelles, Hôpital Henri Mondor, Assistance

Publique - Hôpitaux de Paris, Université Paris XII, Créteil, France; ${ }^{2}$ Service de

Neurochirurgie, Hôpital Henri Mondor, Assistance Publique - Hôpitaux de Paris, Université

Paris XII, Créteil, France.

Correspondence to: Pr Jean-Pascal Lefaucheur, Service Physiologie, Explorations

Fonctionnelles, Hôpital Henri Mondor, 51 avenue de Lattre de Tassigny, 94010 Créteil cedex,

France. Tel.: 3314981 2694. Fax: 3314981 4660. E-mail: jean-pascal.lefaucheur@hmn.ap-

hop-paris.fr

The Corresponding Author has the right to grant on behalf of all authors and does grant on behalf of all authors, an exclusive licence (or non-exclusive for government employees) on a worldwide basis to the BMJ Publishing Group Ltd and its Licensees to permit this article to be published in Journal of Neurology, Neurosurgery and Psychiatry editions and any other BMJPGL products to exploit all subsidiary rights, as set out in our licence http://jnnp.bmjjournals.com/ifora/licence.pdf

Word count for the abstract: 250 ; text: 2,480 .

Number of references: 38; table: 1; figures: 2 .

Running title: Microvascular decompression monitoring

Keywords: Electromyography; Ephapse; Hemifacial Spasm, Intraoperative monitoring;

Lateral spread response; Microvascular decompression; Outcome; Surgery. 


\begin{abstract}
Background: Primary hemifacial spasm (HFS) has specific electrophysiological features, like the existence of lateral spread responses (LSRs) to the stimulation of facial nerve branches. The curative treatment of HFS is based on surgical microvascular decompression (MVD), although the outcome of this procedure is not always satisfactory.
\end{abstract}

Objective: To evaluate the correlation between intraoperative LSR changes after MVD and the short- and long-term postoperative clinical outcomes.

Methods: Thirty-two consecutive patients with primary HFS treated by MVD performed with intraoperative LSR monitoring were retrospectively included. The patients were assessed for the presence of HFS and surgical complications at one day, one month, and six months after surgery. Long-term clinical result was assessed between one and 10 years (mean 5.4 years) using a self-report questionnaire.

Results: Patients were divided into three groups based on intraoperative LSR changes: (i) in 15 patients, LSRs were present before incision and disappeared after MVD (47\%); (ii) in nine patients, LSRs were present before incision but persisted despite MVD (28\%); (iii) in eight patients, LSRs were absent before surgery and remained so after the procedure $(25 \%)$. Intraoperative LSR abolition during the MVD procedure correlated with HFS relief in the long term $(p<0.0001$, Fisher's exact test $)$, but not on the first day after surgery $(p=0.3564)$. Conclusions: Monitoring MVD by intraoperative LSR recording could be of value not only to indicate the resolution of the vasculo-nervous conflict at the end of surgery, but also to indicate a positive clinical outcome in the long term after the surgical intervention. 


\section{Introduction}

Primary hemifacial spasm (HFS) is caused by an intracranial vessel touching the facial nerve near its origin from the brainstem. ${ }^{1-4}$ Vascular compression causes various excitability changes: (i) spontaneous ectopic discharges, leading to spasms; (ii) ephaptic transmission between different facial nerve branches, leading to synkinesis. However, it is still debated whether ephapses are generated at the site of vascular compression, due to focal alteration of myelin sheaths or at level of the facial motor nucleus, triggered by antidromically propagated discharges. $^{1,2}$

This disorder usually results in severe aesthetic and functional disability. Spontaneous recovery is very rare and two treatments can be proposed: botulinum toxin injections and surgical microvascular decompression (MVD) ${ }^{5-8}$ The electrophysiological diagnosis of primary HFS can be established by the presence of lateral spread responses (LSRs) (i.e. upper facial muscle responses to lower facial nerve branch stimulation or lower facial muscle responses to upper facial nerve branch stimulation). ${ }^{9}$ The goal of intraoperative electromyographic monitoring during MVD is to show LSR disappearance when the offending vessel is moved off the facial nerve. ${ }^{10-13}$ However, the value of intraoperative LSR disappearance to predict a good clinical outcome after surgical decompression remains a matter of debate. ${ }^{14-18}$ In particular, HFS can recur later after an apparently successful MVD. ${ }^{19-}$

${ }^{23}$ We readdressed this question in a series of 32 patients who underwent MVD for the treatment of primary HFS with intraoperative LSR recordings. The relationships between LSR disappearance and short- and long-term clinical results were evaluated.

\section{Methods}

Among the patients who underwent MVD for the treatment of primary HFS between 1999 and 2008 at Henri Mondor Hospital, intraoperative electromyographic monitoring was performed in 32 patients (14 women, 18 men). The realization of intraoperative monitoring 
was related to the availability of a trained clinical neurophysiologist in the operating room. There was no other selection bias. Patients were retrospectively included in this study. The main clinical characteristics are presented in Table 1. Eleven patients had right HFS and 21 patients had left HFS. Age at the time of surgery ranged from 34 to 79 years (mean (SD): 55.9 (11.0) years). Duration between HFS onset and surgery ranged from 1 to 30 years (mean (SD): 5.9 (5.5) years). All but two patients were treated by botulinum toxin injections prior to MVD. Fifteen patients underwent more than 10 sessions of botulinum toxin injection in the course of their disease. The time interval between the last injection and surgery was longer than two months in all patients.

Surgery was always performed by the same neurosurgeons, using a standardized procedure considered as the optimal technique. ${ }^{13,24}$ Briefly, the patient was placed in the lateral decubitus position and a small retromastoid craniotomy was performed. The IX ${ }^{\text {th }}$ and $\mathrm{X}^{\text {th }}$ cranial nerves were identified through an infero-lateral approach of the cebellopontine angle. After opening the arachnoid, these nerves were followed along the choroid plexus emerging from the foramen of Luschka. The facial root entry zone was reached close to the brainstem along an infra-floccular route. The offending vessel loop was usually found just ventral to the choroid plexus and was held off the VII ${ }^{\text {th }}$ nerve by interposing a small piece of shredded Teflon or Dacron or both.

Intraoperative LSR recordings were performed at the beginning of the surgical procedure (before incision), before and after the decompression, and at the end of the surgical procedure. No curarizing drugs were administered, except for a single dose of short-acting neuromuscular blocking agent with fast recovery administered for intubation. Electromyographic monitoring technique was as follows. Two pairs of monopolar needle electrodes were used to separately stimulate the major upper and lower branches of the facial nerve on the side of HFS. Two pairs of monopolar needles were placed in the frontalis and mentalis muscles for electromyographic recordings. Electrical stimulation consisted of 
square-wave pulses (intensity: about 10mA; duration: $0.1 \mathrm{~ms}$; cathode proximal) and electromyographic recordings were filtered through a $10 \mathrm{~Hz}-5 \mathrm{kHz}$ bandpass (gain: $500 \mu \mathrm{V} /$ division; analysis time: $50 \mathrm{~ms})$.

All patients were evaluated one day, one month, and six months after the surgical intervention by a neurologist. This physician was unaware of the results of intraoperative monitoring, which were only orally communicated to the neurosurgeon during surgery. Longterm clinical outcome (one to 10 years after MVD) was determined by retrospectively reviewing the medical records of the patients and by prospectively sending a questionnaire to the patients by regular mail. The questionnaire assessed the long term outcome of the procedure (abolished or persistent HFS) and the presence of adverse events (facial palsy or auditory impairment).

The relationship between intraoperative LSR disappearance and short- or long-term clinical outcome (one day, one month, six months, and one to 10 years after surgery) was studied using the Fisher's exact test. A p value less than 0.05 was considered as significant. Positive and negative predictive values of intraoperative LSR disappearance for HFS abolition in the long term, as well as sensibility and sensitivity were calculated.

\section{Results}

The main results are presented in Table 1. The compressing vessel was the postero-inferior cerebellar artery (PICA) in 23 patients (72\%), the vertebro-basilar artery (VB) in 8 patients (25\%), and another vessel in 4 patients. In five patients, the facial nerve was compressed by both PICA and VB. In one patient, vascular compression was not found. In one patient, dissection was stopped after arachnoid opening and before performing MVD because of cerebellar swelling. However, this was sufficient to cure HFS, even in the long term. Two patients were reoperated because HFS persisted after an initial MVD. During the second procedure, the piece of Teflon was found not to be large enough and probably shifted 
sideways, causing the recurrence of the compression. Therefore, a new piece of Teflon was interposed with Dacron at the level of the conflict. In these patients, follow-up data only concerned the second surgical intervention, which turned out to be effective.

No adverse events occurred during surgery. Postoperative complications included mild hearing loss (4 patients) and facial palsy (2 patients). All these complications resolved within a month after surgery under steroid treatment.

Two electromyographic responses were characterized: (i) a direct response (DR) to the stimulation of the 'homonymous' facial nerve branch; and (ii) a LSR to the stimulation of the other facial nerve branch. Two types of DRs were distinguished, according to their morphology and to the duration of their negative peak. In 24 patients, DRs were morphologically normal, biphasic, and of short duration (negative peak duration $\leq 5 \mathrm{~ms}$ ). In eight patients, DRs were abnormally prolonged (negative peak duration $>5 \mathrm{~ms}$ ), polyphasic, and showed an increased temporal dispersion (ITD) (Fig. 1). In six of these eight patients, LSRs were absent. The presence of DRs with ITD was associated with the absence of LSRs ( $p=0.0008$, Fisher's exact test) but not with the number of sessions of botulinum toxin injection $(\mathrm{p}=0.42)$.

Regarding the presence of LSRs before and at the end of surgery, patients were divided into three groups: (i) group 1: LSRs were present before incision and disappeared immediately after MVD (15 patients, 47\%) (Fig. 1); (ii) group 2: LSRs were present before incision and remained so after MVD (9 patients, 28\%); (iii) group 3: LSRs were absent before incision and remained so after MVD (8 patients, 25\%).

Postoperative evolution of HFS is illustrated by a flow diagram (Fig. 2) and individual results are presented in Table 1 . In summary, 24 patients (75\%) were relieved from HFS by the day after surgery. One month after surgery, HFS was abolished in two additional patients from group 1, but recurred in three patients (one from group 1 and two from group 2). Six 
months after surgery, HFS was abolished in three additional patients (one from each group), but recurred in three patients (two from group 2 and one from group 3).

Long-term outcome was assessed on medical records and questionnaires, which showed no discrepancies. The follow-up ranged from 1 to 10 years (mean (SD): 5.4 (3.0) years). Compared to the six-month time point, HFS was abolished in three additional patients (one from each group), but recurred in two patients (from group 2). At the final time point, 24 patients $(75 \%)$ were completely relieved from HFS (all patients from groups 1 and 3 and one patient from group 2), whereas HFS remained present in eight patients (all from group 2).

The association between intraoperative LSR abolition (when LSRs were present before incision) and HFS disappearance was not significant on the day after surgery ( $\mathrm{p}=$ 0.3564 , Fisher's exact test), but was significant at one month $(\mathrm{p}=0.0215)$, six months $(\mathrm{p}=$ 0.0007) and in the long term ( $\mathrm{p}<0.0001)$. In the long term, HFS was abolished in all patients who showed absent LSRs at the end of surgery (whatever the presence or absence of LSRs before incision) but in only one patient (out of nine) in whom LSR persisted at the end of surgery. The sensitivity of LSR abolition to indicate a successful clinical outcome in the long term was $100 \%$, as was the positive predictive value, while the specificity was $94 \%$ and the negative predictive value was $89 \%$.

\section{Discussion}

Several studies have assessed the value of recording LSR during MVD procedure to confirm

the successful decompression of the facial nerve and to predict the postoperative outcome. ${ }^{14-18}$ The disappearance of LSRs usually occurred within a few minutes after Teflon or Dacron pad interposition. However, in at least one patient of our series, LSRs disappeared simply after arachnoid opening, even before MVD. Mooij et al. ${ }^{25}$ reported a similar experience of LSR disappearance after drainage of cerebrospinal fluid. In rare cases, the outflow of cerebrospinal 
fluid may consistently change the anatomical relationship between the facial nerve and a compressive vessel. ${ }^{11,12,19,26}$

Several studies questioned the value of intraoperative LSR monitoring to predict postoperative clinical outcome. ${ }^{13-15,18}$ In fact, we did not find any correlation between intraoperative LSR changes and HFS relief on the first day after surgery. At this time point, HFS was abolished in five patients in whom LSRs persisted at the end of surgery. However, HFS can recur or disappear several months after $\mathrm{MVD},{ }^{27,28}$ and therefore the immediate postoperative result does not always reflect the long-term outcome. Actually, we found that the absence of LSRs at the end of surgery correlated to MVD efficacy in the long term. This important finding was rarely addressed in previous studies, ${ }^{16,17,29}$ and remains to be confirmed in larger series.

One limitation of intraoperative LSR monitoring is that LSRs can be already absent in a subset of patients at the beginning of surgery. In the present study, this condition was associated with the presence of polyphasic DRs with ITD. A figure of a previous paper ${ }^{30}$ showed DR amplitude reduction with ITD, concomitant to the abolition of LSRs, as an effect of botulinum toxin injection in orbicularis oculi muscle for the treatment of HFS. Abundant polyphasic motor unit action potentials were found in the electromyographic activity of injected facial muscles for the treatment of blepharospasm, indicating a certain degree of reinnervation. ${ }^{31}$ In the same context, histological studies revealed persistence of unmyelinated axonal motor sprouts for several years with new end plates and motor unit enlargement, although the paralytic effect of the toxin had disappeared. ${ }^{32,33}$ We hypothesized that both polyphasic DRs with ITD and LSR absence were associated with a process of denervationreinnervation caused by preceding botulinum toxin injections.

However, we did not find an association between the number of botulinum toxin injections and the presence of DRs with ITD. This observation did not rule out our hypothesis. Indeed, in a large series of patients with primary HFS who had received 
botulinum toxin injections regularly for at least 10 years, the overall rate of adverse motor events to the injections (ptosis, facial weakness) significantly diminished over time and the cumulative number of injections. ${ }^{34}$ This result was attributed to optimization of the injection technique over time, because the annual number of injections or dose of toxin did not vary. Actually, complications of botulinum toxin injections, such as the extent of paralysis, depends on the dose used, ${ }^{35}$ the concentration and the type of preparation (serotype) employed, ${ }^{36}$ the injection volume, the interval between the injections, ${ }^{37}$ and also the injection technique (needle gauge, muscle volume, distance of needle tip from the neuromuscular junction). ${ }^{38}$ In the present study, except for the total number of injections and the minimal delay between injections and surgery (two months), we were not able to address the question of all the other parameters. Therefore, side effects of botulinum toxin injections, possibly including the presence of DRs with ITD and absent LSRs, remained unpredictable.

It is also questionable to know whether LSR monitoring leads to modify or not the practical approach made by the neurosurgeon to perform MVD. In the present study, the most frequent offending vessels were PICA and VB, as found in previous reports. ${ }^{4,13,16,26}$ However, several studies showed multiple sites of nerve compression at the origin of primary HFS. ${ }^{3,13,26}$ Therefore the persistence of LSRs despite decompression at a first site could drive the neurosurgeon to search for another site of vascular compression. Such a strategy was nicely developed by Mooij et al. in a previous study. ${ }^{25}$ Briefly, the surgeon first performed MVD at the most obvious site of vasculo-nervous contact. In 53\% of cases, LSRs disappeared following this first decompression and the monitoring was classified as "confirming". If LSRs did not disappear, the exploration was continued. After careful dissection, Mooij et al. found another compression site in most cases. In $34 \%$ of cases, decompression at the second site was followed by LSR disappearance and the monitoring was classified as "guiding". In $7 \%$ of cases, LSRs did not change after MVD and the monitoring was classified as "inconclusive". 
We applied the same strategy as Mooij et al., and we found a second vasculo-nervous conflict in three of 11 patients in whom LSRs persisted following the first decompression. In one of these patients, LSRs persisted after the treatment of the second conflict, and HFS was still present at long-term evaluation. In the two others, LSRs disappeared after the treatment of the second conflict, and long-term clinical result was good. Monitoring was "confirming", "guiding", and "inconclusive" in 52\%, 9\%, and 39\% of the MVD procedures, respectively, when LSRs were present at the beginning of surgery. The lower ratio of "guiding" versus "inconclusive" monitoring in the present study compared to that of Mooij et al., might indicate that we did not explore further enough. Mooij et al. also showed that monitoring helped to find the real and not previously found compression site in two-thirds of the cases of

reoperation. ${ }^{25}$ In contrast, we did not find a second conflict in the two patients who were reoperated because of persisting HFS.

\section{Conclusion}

HFS is a functional impairment that requires MVD for a complete resolution of symptoms. However, the results of MVD are not always satisfactory. The disappearance of LSRs at the end of surgery could be a reliable predictive factor to indicate that the resolution of the vasculo-nervous conflict will lead to a good postoperative result in the long term.

\section{References}

1. Møller AR. Vascular compression of cranial nerves: II: pathophysiology. Neurol Res 1999;21:439-43.

2. Valls-Solé J. Facial palsy, postparalytic facial syndrome, and hemifacial spasm. Mov Disord 2002;17 Suppl 2:S49-52.

3. Sindou MP, Polo G, Fischer C, et al. Neurovascular conflict and hemifacial spasm. Suppl Clin Neurophysiol 2006;58:274-81. 
4. Campos-Benitez M, Kaufmann AM. Neurovascular compression findings in hemifacial spasm. J Neurosurg 2008;109:416-20.

5. Wang A, Jankovic J. Hemifacial spasm: clinical findings and treatment. Muscle Nerve 1998;21:1740-7.

6. McLaughlin MR, Jannetta PJ, Clyde BL, et al. Microvascular decompression of cranial nerves: lessons learned after 4400 operations. J Neurosurg 1999;90:1-8

7. Costa J, Espírito-Santo C, Borges A, Ferreira, et al. Botulinum toxin type A therapy for hemifacial spasm. Cochrane Database Syst Rev 2005;(1):CD004899.

8. Møller AR, Møller MB. Microvascular decompression operations. Prog Brain Res 2007;166:397-400.

9. Valls-Solé J. Electrodiagnostic studies of the facial nerve in peripheral facial palsy and hemifacial spasm.Muscle Nerve 2007;36:14-20.

10. Møller AR, Jannetta PJ. Hemifacial spasm: results of electrophysiologic recording during microvascular decompression operations. Neurology 1985;35:969-74.

11. Møller AR, Jannetta PJ. Monitoring facial EMG responses during microvascular decompression operations for hemifacial spasm. J Neurosurg 1987;66:681-5.

12. Haines SJ, Torres F. Intraoperative monitoring of the facial nerve during decompressive surgery for hemifacial spasm. J Neurosurg 1991;74:254-7.

13. Sindou MP. Microvascular decompression for primary hemifacial spasm. Importance of intraoperative neurophysiological monitoring. Acta Neurochir (Wien) 2005;147:1019-26.

14. Kiya N, Bannur U, Yamauchi A, et al. Monitoring of facial evoked EMG for hemifacial spasm: a critical analysis of its prognostic value. Acta Neurochir (Wien) 2001;143:365-8.

15. Hatem J, Sindou M, Vial C. Intraoperative monitoring of facial EMG responses during microvascular decompression for hemifacial spasm. Prognostic value for long-term outcome: a study in a 33-patient series. Br J Neurosurg 2001;15:496-9. 
16. Yamashita S, Kawaguchi T, Fukuda M, et al. Abnormal muscle response monitoring during microvascular decompression for hemifacial spasm. Acta Neurochir (Wien) 2005;147:933-7.

17. Kong DS, Park K, Shin BG, et al. Prognostic value of the lateral spread response for Intraoperative electromyography monitoring of the facial musculature during microvascular decompression for hemifacial spasm. J Neurosurg 2007;106:384-7.

18. Joo WI, Lee KJ, Park HK, et al. Prognostic value of intra-operative lateral spread response monitoring during microvascular decompression in patients with hemifacial spasm. J Clin Neurosci 2008;15:1335-9.

19. Li CS. Varied patterns of postoperative course of disappearance of hemifacial spasm after microvascular decompression. Acta Neurochir (Wien) 2005;147:617-20.

20. Goto Y, Matsushima T, Natori Y, et al. Delayed effects of the microvascular decompression on hemifacial spasm: a retrospective study of 131 consecutive operated cases. Neurol Res 2002;24:296-300.

21. Engh JA, Horowitz M, Burkhart L, et al. Repeat microvascular decompression for hemifacial spasm. J Neurol Neurosurg Psychiatry 2005;76:1574-80.

22. Park YS, Chang JH, Cho J, et al. Reoperation for persistent or recurrent hemifacial spasm after microvascular decompression. Neurosurgery 2006;58:1162-7.

23. Huh R, Han IB, Moon JY, et al. Microvascular decompression for hemifacial spasm: analyses of operative complications in 1582 consecutive patients. Surg Neurol 2008;69:153-7.

24. Møller AR. Vascular compression of cranial nerves. I. History of the microvascular decompression operation. Neurol Res 1998;20:727-31.

25. Mooij JJ, Mustafa MK, van Weerden TW. Hemifacial spasm: intraoperative electromyographic monitoring as a guide for microvascular decompression. Neurosurgery 2001;49:1365-70. 
26. Park JS, Kong DS, Lee JA, et al. Hemifacial spasm: neurovascular compressive patterns and surgical significance. Acta Neurochir (Wien) 2008;150:235-41.

27. Payner TD, Tew JM Jr. Recurrence of hemifacial spasm after microvascular decompression. Neurosurgery 1996;38:686-90.

28. Ishikawa M, Nakanishi T, Takamiya Y, et al. Delayed resolution of residual hemifacial spasm after microvascular decompression operations. Neurosurgery 2001;49:847-54.

29. Fukuda M, Yamashita S, Kawaguchi T, et al. [Abnormal muscle response monitoring during microvascular decompression for hemifacial spasm and long term results]. No Shinkei Geka 2006;34:583-9.

30. Glocker FX, Guschlbauer B, Lücking CH, et al. Effects of local injections of botulinum toxin on electrophysiological parameters in patients with hemifacial spasm: role of synaptic activity and size of motor units. Neurosci Lett 1995;187:161-4.

31. Valls-Sole J, Tolosa ES, Ribera G. Neurophysiological observations on the effects of botulinum toxin treatment in patients with dystonic blepharospasm. $J$ Neurol Neurosurg Psychiatry 1991;54:310-3.

32. Holds JB, Alderson K, Fogg SG, et al. Motor nerve sprouting in human orbicularis muscle after botulinum A injection. Invest Ophthalmol Vis Sci 1990;31:964-7.

33. Alderson K, Holds JB, Anderson RL. Botulinum-induced alteration of nerve-muscle interactions in the human orbicularis oculi following treatment for blepharospasm. Neurology 1991;41:1800-5.

34. Defazio G, Abbruzzese G, Girlanda P, et al. Botulinum toxin A treatment for primary hemifacial spasm: a 10-year multicenter study. Arch Neurol 2002;59:418-20.

35. Borodic GE, Ferrante R, Pearce LB, et al. Histologic assessment of dose-related diffusion and muscle fiber response after therapeutic botulinum A toxin injections. Mov Disord 1994;9:31-9. 
36. Rosales RL, Bigalke H, Dressler D. Pharmacology of botulinum toxin: differences between type A preparations. Eur J Neurol 2006;13 Suppl 1:2-10.

37. Borodic GE, Ferrante R. Effects of repeated botulinum toxin injections on orbicularis oculi muscle. J Clin Neuroophthalmol 1992;12:121-7.

38. Lim EC, Seet RC. Botulinum toxin: description of injection techniques and examination of controversies surrounding toxin diffusion. Acta Neurol Scand 2008;117:73-84. 


\section{Legends for the figures and the table}

\section{Figure 1.}

A. Examples of electromyographic recordings in patients with primary hemifacial spasm before microvascular decompression (MVD). Left traces: the stimulation of the upper facial nerve evoked a biphasic direct reponse (DR) with short latency in the frontalis muscle and a lateral spread response (LSR) with longer latency in the mentalis muscle. Right traces: the stimulation of the upper facial nerve evoked a DR with increased temporal dispersion (ITD) and no LSR.

B. Following successful MVD, the DRs to the stimulation of the 'homonymous' facial nerve branch remained unchanged whereas the LSRs to the stimulation of the other facial nerve branch were abolished. Horizontal bar: $3 \mathrm{~ms}$. Vertical bar: $1 \mathrm{mV}$.

\section{Figure 2.}

Flow diagram illustrating the clinical evolution over time of the 32 patients with primary hemifacial spasm (HFS) treated by microvascular decompression (MVD). Groups were defined according to the presence or absence of lateral spread response (LSR) before and after MVD.

\section{Table1.}

Main characteristics of the 32 patients with primary hemifacial spasm (HFS), including electrophysiological and clinical results following microvascular decompression (MVD). Bot.: botulinum; DR: direct response; LSR: lateral spread response; PICA: postero-inferior cerebellar artery; VB: vertebro-basilar artery; nml: normal; ITD: increased temporal dispersion. 


\begin{tabular}{|c|c|c|c|c|c|c|c|c|c|c|c|c|c|c|}
\hline Patient & Sex & $\begin{array}{l}\text { Age } \\
\text { (years) }\end{array}$ & $\begin{array}{l}\text { Duration of } \\
\text { HFS pre-MVD } \\
\text { (years) }\end{array}$ & $\begin{array}{l}\text { HFS } \\
\text { side }\end{array}$ & $\begin{array}{l}\text { Offending } \\
\text { vessel }\end{array}$ & $\begin{array}{l}\text { Bot. toxin } \\
\text { injections } \\
(* \mathbf{n}>10)\end{array}$ & DR & $\begin{array}{l}\text { LSR } \\
\text { pre- } \\
\text { MVD }\end{array}$ & $\begin{array}{l}\text { LSR } \\
\text { post- } \\
\text { MVD }\end{array}$ & $\begin{array}{l}\text { HFS at } \\
\text { day } 1\end{array}$ & $\begin{array}{l}\text { HFS at } \\
\text { month } 1\end{array}$ & $\begin{array}{l}\text { HFS at } \\
\text { month } 6\end{array}$ & $\begin{array}{l}\text { HFS at } \\
\text { long } \\
\text { term }\end{array}$ & $\begin{array}{l}\text { Post-MVD } \\
\text { follow-up } \\
\text { duration (years) } \\
(* * \text { 2nd surgery) }\end{array}$ \\
\hline 1 & $\mathrm{~m}$ & 41 & 2 & right & other & yes & $\mathrm{nml}$ & yes & yes & no & yes & yes & yes & 10 \\
\hline 2 & $\mathrm{~m}$ & 44 & 4 & left & PICA & yes & $\mathrm{nml}$ & yes & no & no & yes & yes & no & 10 \\
\hline 3 & $\mathrm{w}$ & 54 & 1 & left & PICA & yes & $\mathrm{nml}$ & yes & no & no & no & no & no & 10 \\
\hline 4 & $\mathrm{~m}$ & 67 & 10 & left & other & yes* & $\mathrm{nml}$ & yes & no & no & no & no & no & 9 \\
\hline 5 & $\mathrm{~m}$ & 37 & 7 & right & PICA & yes* & $\mathrm{nml}$ & yes & no & no & no & no & no & 9 \\
\hline 6 & $\mathrm{~m}$ & 53 & 4 & left & PICA, VB & yes & $\mathrm{nml}$ & yes & yes & no & no & yes & yes & 9 \\
\hline 7 & $\mathrm{w}$ & 70 & 30 & left & PICA & yes* & $\mathrm{nml}$ & yes & yes & no & yes & yes & yes & 9 \\
\hline 8 & $\mathrm{~m}$ & 52 & 2 & left & PICA, VB & yes & $\mathrm{nml}$ & no & no & no & no & no & no & 8 \\
\hline 9 & $\mathrm{~m}$ & 38 & 1 & right & not reached & no & $\mathrm{nml}$ & yes & no & yes & no & no & no & 8 \\
\hline 10 & $\mathrm{~m}$ & 59 & 3 & left & VB & yes & $\mathrm{nml}$ & yes & yes & yes & yes & no & yes & 8 \\
\hline 11 & $\mathrm{~m}$ & 64 & 15 & left & VB & yes* & $\mathrm{nml}$ & yes & no & no & no & no & no & 8 \\
\hline 12 & $\mathrm{w}$ & 57 & 4 & right & PICA & yes & $\mathrm{nml}$ & yes & no & no & no & no & no & 8 \\
\hline 13 & $\mathrm{~m}$ & 63 & 4 & left & PICA, VB & yes & $\mathrm{nml}$ & yes & no & yes & no & no & no & 8 \\
\hline 14 & $\mathrm{~m}$ & 70 & 4 & left & PICA, VB & yes & $\mathrm{nml}$ & yes & no & no & no & no & no & 7 \\
\hline 15 & $\mathrm{w}$ & 54 & 8 & left & PICA & yes* & $\mathrm{nml}$ & yes & yes & yes & yes & yes & yes & 7 \\
\hline 16 & $\mathrm{w}$ & 53 & 2 & right & other & no & $\mathrm{nml}$ & yes & yes & no & no & yes & yes & 7 \\
\hline 17 & $\mathrm{w}$ & 42 & 3 & left & PICA, VB & yes* & ITD & no & no & no & no & no & no & 7 \\
\hline 18 & $\mathrm{~m}$ & 54 & 7 & right & PICA & yes* & $\mathrm{nml}$ & yes & no & no & no & no & no & 7 \\
\hline 19 & $\mathrm{~m}$ & 34 & 2 & left & PICA & yes & ITD & no & no & no & no & yes & no & 5 \\
\hline 20 & w & 74 & 10 & left & PICA & yes* & $\mathrm{nml}$ & no & no & yes & yes & no & no & 5 \\
\hline 21 & w & 56 & 8 & left & PICA & yes* & $\mathrm{nml}$ & yes & no & yes & yes & no & no & 4 \\
\hline 22 & w & 56 & 8 & left & PICA & yes* & $\mathrm{nml}$ & yes & no & no & no & no & no & 4 \\
\hline 23 & w & 59 & 5 & left & PICA & yes & $\mathrm{nml}$ & yes & no & no & no & no & no & $3 * *$ \\
\hline 24 & $\mathrm{~m}$ & 51 & 7 & left & PICA & yes* & $\mathrm{nml}$ & yes & yes & no & no & no & yes & 3 \\
\hline 25 & $\mathrm{~m}$ & 61 & 2 & left & PICA & yes & ITD & no & no & no & no & no & no & 2 \\
\hline 26 & $\mathrm{w}$ & 43 & 3 & right & PICA & yes* & ITD & yes & yes & yes & yes & yes & no & $2 * *$ \\
\hline 27 & $\mathrm{~m}$ & 61 & 1 & left & other & yes & ITD & no & no & no & no & no & no & 2 \\
\hline 28 & $\mathrm{~m}$ & 60 & 3 & left & VB & yes & $\mathrm{nml}$ & yes & no & no & no & no & no & 1 \\
\hline 29 & w & 51 & 10 & right & not found & yes* & ITD & no & no & no & no & no & no & 1 \\
\hline 30 & $\mathrm{~m}$ & 66 & 10 & right & PICA & yes* & ITD & yes & yes & yes & yes & yes & yes & 1 \\
\hline 31 & $\mathrm{w}$ & 65 & 4 & right & PICA & yes* & ITD & no & no & no & no & no & no & 1 \\
\hline 32 & $\mathrm{w}$ & 79 & 5 & right & PICA & yes & $\mathrm{nml}$ & yes & no & no & no & no & no & 1 \\
\hline
\end{tabular}


A. Relationship between dispersion of the direct response and absence of lateral spread response at baseline

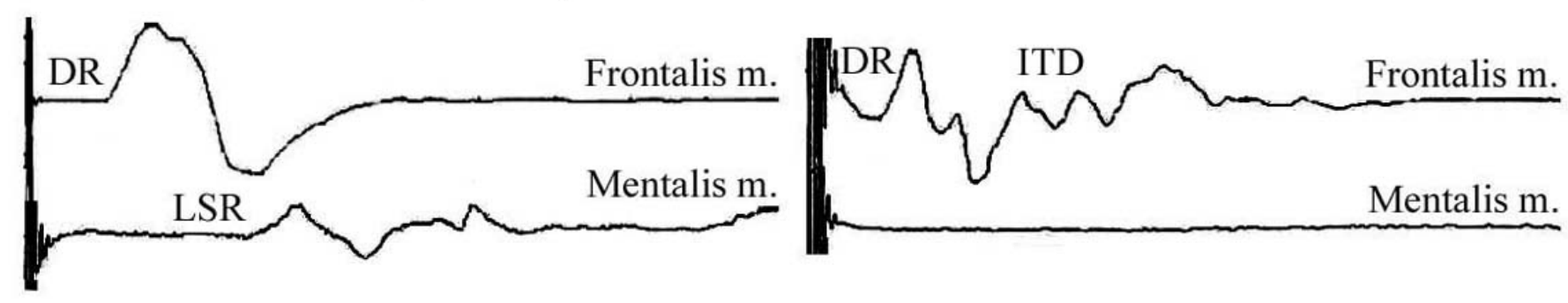

B. Abolition of the lateral spread responses after microvascular decompression

Before incision
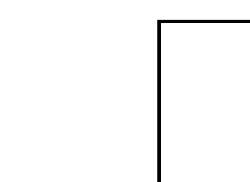
LSR+$$
(n=24)
$$

LSR-

$(\mathrm{n}=8)$

End of

surgery

Day 1

postop.

Month 1

postop.



